\title{
Peripheries of the Enlightenment, Edited by Richard Butterwick, Simon Davies and Gabriel Sánchez Espinoza
}

\section{Regina Bochenek-Franczakowa}

\section{(2) OpenEdition Journals \\ Édition électronique \\ URL : http://journals.openedition.org/studifrancesi/7931 \\ DOI : 10.4000/studifrancesi.7931 \\ ISSN : 2421-5856 \\ Éditeur \\ Rosenberg \& Sellier}

\section{Édition imprimée}

Date de publication : 1 juillet 2009

Pagination : $399-400$

ISSN : 0039-2944

\section{Référence électronique}

Regina Bochenek-Franczakowa, «Peripheries of the Enlightenment, Edited by Richard Butterwick, Simon Davies and Gabriel Sánchez Espinoza », Studi Francesi [En ligne], 158 (LIII | II) | 2009, mis en ligne le 30 novembre 2015, consulté le 13 janvier 2021. URL : http://journals.openedition.org/ studifrancesi/7931; DOI : https://doi.org/10.4000/studifrancesi.7931

Ce document a été généré automatiquement le 13 janvier 2021.

\section{cc) (†) $\odot$}

Studi Francesi è distribuita con Licenza Creative Commons Attribuzione - Non commerciale - Non opere derivate 4.0 Internazionale. 


\title{
Peripheries of the Enlightenment, Edited by Richard Butterwick, Simon Davies and Gabriel Sánchez Espinoza
}

\author{
Regina Bochenek-Franczakowa
}

\section{RÉFÉRENCE}

Peripheries of the Enlightenment, Edited by Richard BUTTERWICK, Simon DAVIES and Gabriel SÁNCHEZ ESPINOZA, Oxford, Voltaire Foundation, 2008 («SVEC 2008:1»), pp. 340.

1 Les études contenues dans cet ouvrage sont consacrées à l'exploration des «périphéries» des Lumières. Comme le rappelle Richard BUTTERwick (Peripheries of the Enlightenment: an introduction, pp. 1-16), l'insuffisante connaissance du contexte historique obscurcit l'approche des Lumières européennes dans leur ensemble et leur complexité. Les études touchent à divers aspects de ce que l'on nomme "périphérique», par rapport au «centre», en premier lieu, la France. Simon DAviES (Whither/wither France: Votlaire's view from Ferney, pp. 17-27) rappelle que, paradoxalement, c'est du «périphérique» Ferney en Suisse que Voltaire, le Parisien, mena sa campagne pour «éclairer» ses compatriotes et l'humanité. Selon Graham GARGETT (French periphery, European centre: eighteenth-century Geneva and its contribution to the Enlightenment, pp. 29-47), malgré sa dimension modeste, Genève joua un rôle important dans les Lumières françaises. Paradoxalement, la cité calviniste est devenue 'libérale'; la présence de Voltaire et les liens avec Rousseau forment une contribution ambiguë de la ville au progrès de la pensée politique et religieuse des Lumières. Michael BROWN (Was there an Irish Enlightenment? The case of the Anglicans, pp. 49-63), à l'encontre de l'historiographie dominante, veut prouver qu'une variante irlandaise des Lumières existait, quoique particulière. Il tient à démontrer que la notion de «périphérie» risque de dévaloriser 
l'apport de l'Irlande aux Lumières anglaises. Une autre approche des Lumières irlandaises est proposée par Ultán GILLEN (Varieties of Enlightenment: the Enlightenment and Irish political culture in the age of revolutions, pp. 163-181): dans l'Irlande des années 1790 se fait jour l'influence des Lumières dans le domaine de la pensée politique, largement influencée par la Révolution française et les Lumières écossaises. L'article explique pourquoi la langue des Lumières fut si importante dans la culture politique irlandaise à la fin du XVIII 'siècle. John ROBERTSON (Political economy and the 'feudal system' in Enlightenment Naples: outline of a problem, pp. 65-86) examine les efforts des penseurs à Naples qui, s'inspirant de la philosophie française dans le domaine de l'économie politique, cherchaient des solutions pour réformer le régime économique encore féodal de leur pays. Marie-Christine SKUNCKE (Jean-Jacques Rousseau in Swedish eyes around 1760, pp. 87-103) fait observer qu'en Suède, au milieu du XvIII ${ }^{\mathrm{e}}$ siècle, l'élite rejetait l'œuvre de J.-J. Rousseau car à l'époque y dominait la foi optimiste dans le progrès. Ce sera à la génération des années 1780 de se tourner vers Emile et de propager le nouvel idéal pédagogique. Orsolya SZAKÁLY (Enlightened self-interest: the development of an entrepreneurial culture with Hungarian elite, pp. 105-118) cherche à prouver que les Lumières en Hongrie avaient non seulement la dimension littéraire et linguistique qu'on lui reconnaît mais que l'élément économique (l'établissement des entreprises d'industrie par les nobles) y joua aussi un rôle important. Martin FRITZPATRICK (The view from Mount Pleasant: Enlightenment in late-eighteenth-century Liverpool, pp. 119-144) considère les relations entre le commerce, la culture et les Lumières dans le port de Liverpool à la fin du siècle. Trouver le rapport entre les activités à l'échelle locale et celles qui visent des thèmes généraux de l'humanité (ici: l'esclavage) est un problème que les Liverpooliens réussirent à résoudre. Simon BURRows (Grub Street revolutionaries: marginal writers at the Enlightenment's periphery?, pp. 145-161) révise l'interprétation de Robert Darnton de la «littérature proscrite» et des libellistes français exilés à Londres, quant à leur importance pour la Révolution: cet article tente de réapprécier le phénomène, suggérant que cette activité a été mal comprise et exagérée par les historiens. Gabriel SÁNCHEZ EsPINOZA (An 'ilustrado' in his province: Jovellanos in Asturias, pp. 183-200) considère les écrits personnels de Jovellanos, une des figures les plus importantes des Lumières espagnoles. Revenu à deux fois dans son pays natal très arriéré, Jovellanos fait preuve d'un grand enthousiasme dans sa vision utopique des réformes des institutions à l'échelle régionale. Richard BUTTERwick (Between AntiEnlightenment and enlightened Catholicism: provincial preachers in late-eighteenth-century Poland-Lithuania, pp. 201-228) considère les zones limitrophes entre les Lumières et les anti-Lumières, sur l'exemple de plusieurs prédicateurs en Pologne et dans le Grand Duché de Lithuanie, alors que la période, qui menait à la proclamation de la Constitution du 3 mai 1791, fit émerger la Pologne de la périphérie intellectuelle de l'Europe. Simon Dixon ('Prosveshchenie': Enlightenment in eighteenth-century Russia, pp. 229-249) découvre la variété de l'emploi du mot «lumières» dans des textes de caractère fort divers. Il s'avère que, si le sens du mot est généralement lié aux idées de réforme, de progrès, les écrivains russes l'emploient rarement et, à partir des années 1790, dans un sens négatif. Fiona CLARK (The "Gazeta de Literatura de México" and the edge of reason: when is a periphery not a periphery?, pp. 251-264) étudie comment le périodique le plus important de la Nouvelle Espagne, Gazeta de Literatura de México a fait partie d'un échange et de contrôle au niveau local et international. L'A. s'interroge sur les concepts de centre et de périphérie, dans la perspective de la pensée du sociologue Edward Shils. Dans l'article de Lynda PRATT (Tea and national history? Ann Yearsley, John Thelwall and 
late-eighteenth-century provincial English epic, pp. 265-279), l'analyse des poèmes épiques de poètes provinciaux, Ann Yearsley et John Thelwall sert à démontrer le rôle de la culture provinciale dans la constitution de la littérature et l'identité nationales aux $\mathrm{XVIII}^{\mathrm{e}}$ et $\mathrm{XIX}^{\mathrm{e}}$ siècles. Les écrivains provinciaux se posent aussi des questions sur le centre et la périphérie de la culture. Peter Hans R EILL (The Enlightenment from the German periphery: Johann Herder's reinterpretation of the Enlightenment, pp. 281-288) considère la pensée de Herder qui traitait les Lumières françaises non sans criticisme: le cas du penseur allemand vivant en Europe centrale est fort approprié pour étudier la question $\mathrm{du}$ «centre» et de la «périphérie» dans la vie intellectuelle.

2 Les plus grands mérites de ce volume sont, d'un côté, les multiples points de vue qui ont permis aux auteurs d'explorer les régions limitrophes des Lumières; de l'autre, c'est le caractère interdisciplinaire des approches qui sont l'œuvre d'historiens de la littérature, de la philosophie, de la religion, de la science et de l'économie. 